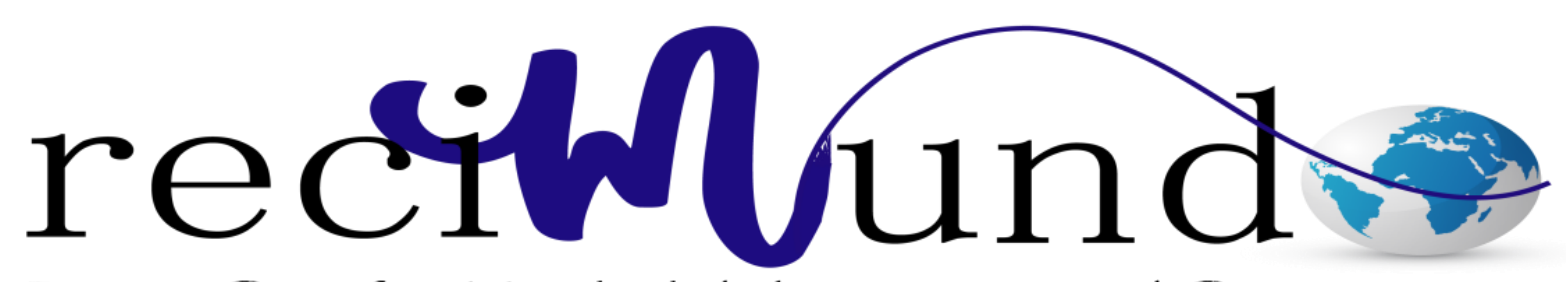

Revista Científica Mundo de la Investigación y el Conocimiento

Carlos Armando Zambrano Zunino a ; Lissette Yesenia Rosero Ortega b; María Stephania Limones Moncada ${ }^{c}$; Mariana Yadira Campaña Davila ${ }^{\text {; }}$ Jacqueline Amalia Parra Zamora ${ }^{\mathrm{e}}$

Un acercamiento a la toxoplasmosis cerebral y su diagnóstico imagenológico

An approach to cerebral toxoplasmosis and its imaging diagnosis

Revista Científica Mundo de la Investigación y el Conocimiento. Vol. 3 núm.1, enero, ISSN: 2588-073X, 2019, pp. 1558-1578

DOI: $\underline{10.26820 / \text { recimundo/3.(1).enero.2019.1558-1578 }}$

URL: http://www.recimundo.com/index.php/es/article/view/431

Código UNESCO: 3207 Patología

Tipo de Investigación: Artículo de Investigación

Editorial Saberes del Conocimiento

Recibido: 20/11/2018

Aceptado: 05/01/2019

Publicado: 31/01/2019

a. Especialista en Ginecología y Obstetricia; Doctor en Medicina y Cirugía; armandozambrano_58@hotmail.com

b. Médica; lissetterosero94@gmail.com

c. Médico; sol-nia@hotmail.com

d. Médico; danamycd@hotmail.com

e. Especialista en Ginecología y Obstetricia; Diploma Superior en Enfermedades Inmunodeficientes en VIH-Sida; Doctora en Medicina y Cirugía; jacquelineshantal@ hotmail.com 


\section{Un acercamiento a la toxoplasmosis cerebral y su diagnóstico imagenológico}

Vol. 3, núm. 1., (2019)

Carlos Armando Zambrano Zunino; Lissette Yesenia Rosero Ortega; Maria Stephania Limones Moncada; Mariana Yadira Campaña Davila; Jacqueline Amalia Parra Zamora

\section{RESUMEN}

Se realizó una revisión minuciosa de la literatura de 10 referencias bibliográficas con un gran alto de actualización en bases de datos como Scielo, concerniente a la Toxoplasmosis, infección zoonótica, causada por el parasito Toxoplasma gondii. Entre los principales aspectos tratados se encuentran: la epidemiología, mecanismo de transmisión, manifestaciones clínicas, diagnóstico, tratamiento y medicas de prevención, enfatizando en Toxoplasmosis cerebral y su diagnóstico por neuroimagen.

Palabras Claves: Toxoplasmosis; Manifestaciones Clínicas; Diagnóstico. 


\section{Un acercamiento a la toxoplasmosis cerebral y su diagnóstico imagenológico}

Vol. 3, núm. 1., (2019)

Carlos Armando Zambrano Zunino; Lissette Yesenia Rosero Ortega; Maria Stephania Limones Moncada; Mariana Yadira Campaña Davila; Jacqueline Amalia Parra Zamora

\section{ABSTRACT}

A thorough literature review of 10 bibliographical references was made with a high update rate in databases such as Scielo, concerning Toxoplasmosis, a zoonotic infection, caused by the parasite Toxoplasma gondii. Among the main aspects discussed are: epidemiology, transmission mechanism, clinical manifestations, diagnosis, treatment and prevention medicine, emphasizing on cerebral toxoplasmosis and its diagnosis by neuroimaging.

Key Words: Toxoplasmosis, Clinical Manifestations, Diagnosis. 


\section{Un acercamiento a la toxoplasmosis cerebral y su diagnóstico imagenológico}

Vol. 3, núm. 1., (2019)

Carlos Armando Zambrano Zunino; Lissette Yesenia Rosero Ortega; Maria Stephania Limones Moncada; Mariana Yadira Campaña Davila; Jacqueline Amalia Parra Zamora

\section{Introducción.}

La toxoplasmosis es una infección causada por el parásito Toxoplasma gondii, afectando aproximadamente el $30 \%$ de la población humana, aunque también puede afectar a una gran variedad de especies animales causando una zoonosis de distribución cosmopolita. La transmisión de este parásito puede causar desde una enfermedad leve y auto limitada en individuos sanos hasta una enfermedad grave en individuo inmunocomprometidos, es potencialmente capaz de parasitar y multiplicarse rápidamente en las células nucleadas de todos los animales homeotermos.

El Toxoplasma gondii tiene afinidad por la especie felina convirtiéndolo en su hospedero definitivo usando las células del epitelio intestinal del felino, para multiplicarse asexuadamente y luego terminar con la multiplicación, haciendo creer por muchos años que el contacto con gatos es la principal vía para adquirir la zoonosis, desconociendo que hay otros factores que presentan mayor riesgo de infección como la ingesta de alimentos contaminados (la presencia de quistes de toxoplasma en carnes mal cocidas), así mismo otras formas no tan comunes como la contaminación en transfusiones de sangre, trasplante de órganos entre otras.

Este gérmen fue descubierto en el mismo momento por Nicolle y Manceaux en Túnez y por Splendore en Brasil en 1908, el nombre hace referencia a su forma (toxo=arco) y gondii por habérsele encontrado en un roedor norafricano (Ctenodactylus gondii). El Toxoplasma gondii es un parásito intracelular, protozoario, que taxonómicamente pertenece a el phylum Apicomplexa, clase Sporozoea, subclase Coccidia, orden Eucoccidiidae, suborden Eimeriina, familia 


\section{Un acercamiento a la toxoplasmosis cerebral y su diagnóstico imagenológico}

Vol. 3, núm. 1., (2019)

Carlos Armando Zambrano Zunino; Lissette Yesenia Rosero Ortega; Maria Stephania Limones Moncada; Mariana Yadira Campaña Davila; Jacqueline Amalia Parra Zamora

Sarcocystidae. Puede presentarse en diferentes estadios como son el ooquiste, el taquizoítos y el quiste.

En 1951, varios investigadores incluyendo a Frenkel y Friedlander, reconocieron otro estado de $T$. gondii, una forma quística, presente en los tejidos de diferentes hospederos. En 1923, se reportó el primer caso confirmado de toxoplasmosis en humanos por Jankú, en un niño de 16 meses de edad, que falleciera, habiendo presentado hidrocefalia, convulsiones y corioretinitis. En Europa, el primer caso diagnosticado in vivo, fue realizado en Suiza por F. Bamatter en un infante, en $1946 .^{1}$

El protozoario es un endoparásito intracelular, de ubicación intra citoplasmática de numerosos tipos de células y parasita numerosas especies entre estas las aves, mamíferos y también al ser humano Puede producir una enfermedad con graves consecuencias principalmente en los humanos y animales en gestación, esta enfermedad conocida como toxoplasmosis, tiene afinidad por la especie felina ya que ellos son los únicos animales en los cuales el parásito se multiplica sexuadamente en el intestino, por lo que se le conocen a los felinos como el hospedero definitivo. ${ }^{2}$

\section{Epidemiología}

La toxoplasmosis es una infección zoonótica, causada por el parasito Toxoplasma gondii. Se calcula que aproximadamente el $50 \%$ de la población mundial es seropositiva a anticuerpos de Toxoplasma gondii, sin embargo, hay ciertas variaciones en las diferentes regiones geográficas lo cual favorece el desarrollo de la zoonosis más que en otras partes del mundo como son los países tropicales. Se estima que aproximadamente el 50\% de población felina son 


\section{Un acercamiento a la toxoplasmosis cerebral y su diagnóstico imagenológico}

Vol. 3, núm. 1., (2019)

Carlos Armando Zambrano Zunino; Lissette Yesenia Rosero Ortega; Maria Stephania Limones Moncada; Mariana Yadira Campaña Davila; Jacqueline Amalia Parra Zamora

portadores del parasito y pueden llegar a ser infectantes en algún momento de su vida. Las formas en que el parásito llega a infectar al ser humano son muy variadas. Siendo la vía oral el factor más predisponente a la transmisión, pero sin ser menos importantes otros factores como el agua, el contacto con heces felinas, y otras formas no tan conocidas como lo son la vía transfusional, trasplantes de órganos, la vía acuática, la mecánica, la inhalación de ooquistes y la vía sexual. La infestación se presenta después de la ingesta de cualquiera de los tres estadios de vida del organismo o por vía trasplacentaría, luego de la cual ocurre una replicación de taquizoítos que infectan una amplia variedad de células del hospedado en los cuales se encuentran especies como roedores, lagomorfos, insectívoros, carnívoros, marsupiales, primates, equinos, incluso el hombre, en aves se ha descrito también en numerosas especies, tales como gallinas, palomas y canarios. Entre los diferentes factores que pueden predisponer el contagio del ser humano con el toxoplasma gondii se encuentra la ingesta del ooquistes procedentes del suelo contaminado con las materias fecales del gato parasitado o la ingestión el contagio por medio de los pseudoquistes o quistes presentes en carnes crudas o mal cocidas. También puede ser transmitida del parásito de la madre al hijo, esto puede ocurrir cuando la infección se adquiere por primera vez durante el embarazo y aumenta la probabilidad de contagio gradualmente con el progreso de la gestación encontrándose un riesgo global de trasmisión del 29\%.

El taquizoítos ingresa al interior de las células del huésped, en el ser humano puede ser cualquier célula nucleada, entre las que se encuentran: leucocitos mononucleares, células endoteliales, células intersticiales, fibras musculares, neuronas, células pulmonares y hepáticas, siendo protegido por medio de una vacuola parasitófora que le confiere protección contra la 


\section{Un acercamiento a la toxoplasmosis cerebral y su diagnóstico imagenológico}

Vol. 3, núm. 1., (2019)

Carlos Armando Zambrano Zunino; Lissette Yesenia Rosero Ortega; Maria Stephania Limones Moncada; Mariana Yadira Campaña Davila; Jacqueline Amalia Parra Zamora

respuesta inmune del huésped, en el interior de las células se multiplican asexualmente hasta romper la membrana celular de la célula parasitada.

Los felinos salvajes y los felinos domésticos son los portadores y hospedadores definitivos, quienes tienen la capacidad de liberan al medio ambiente la forma resistente del parásito, los ooquistes.

\section{Prevalencia de Toxoplasma gondii en otros países tropicales de américa latina}

La prevalencia de la infección por T. gondii a nivel mundial varía de acuerdo a diferentes factores culturales, geográficos, climáticos, económicos. Puede superar el $50 \%$ en perros, conejos y nutrias de mar; el $60 \%$ en ratones, ratas y aves silvestres y el $70 \%$ en gatos, osos y ciervos.

En Cuba se presenta una prevalencia de anticuerpos para toxoplasma gondii en la Habana de $72,72 \%$ en perros que viven expuestos al medio, mientras que en Perú se han reportado seroprealencia en diversas especies domésticas llamas entre 10 y 32\%, alpacas 21 y $53 \%$ porcinos $27.7 \%$, bovinos $17 \%$, caprinos $57.9 \%$.

La seroprealencia en México se encuentra entre el 15 y el 50\% de infección presentando más prevalencia en las regiones costeras húmedas. Brasil presento Seroprealencia en seres humanos de un $70,00 \% \quad 69,08 \%$ en zonas rurales, $72,60 \%$ comunidad urbana de barrios marginales.

En Uruguay, se realizaron estudios para la prevalencia en mujeres embarazadas donde se presentó una prevalencia del $53 \%$. 


\section{Un acercamiento a la toxoplasmosis cerebral y su diagnóstico imagenológico}

Vol. 3, núm. 1., (2019)

Carlos Armando Zambrano Zunino; Lissette Yesenia Rosero Ortega; Maria Stephania Limones Moncada; Mariana Yadira Campaña Davila; Jacqueline Amalia Parra Zamora

En Venezuela se presenta una prevalencia general entre 0,6 y $3 \%$ de las gestantes adquiriendo la infección durante el embarazo. La prevalencia promedio de serorreactividad contra T. gondii supera el 50\%. En Paraguay se encontró una prevalencia de 9,1\% de cicatrices por retinocoroiditis por toxoplasmosis, que se puede considerar alta en comparación con la reportada en estudios poblacionales de otros países. $^{3}$

\section{Mecanismos de transmisión}

a) Por el consumo de ooquistes infectantes que son eliminados con las heces de los gatos y distribuidos en el ambiente a través de la lluvia, el aire y el tránsito de vectores mecánicos como artrópodos, aves y pequeños mamíferos, que contaminan así el agua y la tierra. La ingesta de ooquistes se da cuando el individuo tiene contacto directo con tierra, como en las labores de jardinería, agricultura y la limpieza del arenero de los gatos sin utilizar guantes ni lavarse las manos después de concluir la tarea y por la ingesta de agua, frutas y verduras contaminadas.

b) Por el consumo o manipulación de carne cruda o mal cocida con quistes tisulares de $T$. gondii, principalmente carne de cordero, cerdo, cabra, oso y en menor proporción carne de res, caballo, conejo y aves.

c) Congénita. La infección del feto se da por la vía transplacentaria, y la afectación depende del tercio de la gestación en la que se infecte la madre.

d) Por trasplante de órganos, transfusión sanguínea e inoculación accidental en laboratorios. 


\section{Un acercamiento a la toxoplasmosis cerebral y su diagnóstico imagenológico}

Vol. 3, núm. 1., (2019)

Carlos Armando Zambrano Zunino; Lissette Yesenia Rosero Ortega; Maria Stephania Limones Moncada; Mariana Yadira Campaña Davila; Jacqueline Amalia Parra Zamora

\section{Manifestaciones clínicas}

Toxoplasmosis adquirida en hospedero inmunocompetente. Es asintomática en el $90 \%$ de los casos. El período de incubación es de 10 a 14 días. Se presenta inflamación de linfonodos cervicales y occipitales moderada, mal estado general, linfadenopatía supraclavicular e inguinal, fiebre moderada, odinofagia, cefalea y mialgias. En ocasiones se presenta anorexia, náusea, vómito y dolor abdominal. Podría encontrarse hepatoesplenomegalia, cuadro pulmonar o cardíaco, conjuntivitis y erupción cutánea. La toxoplasmosis aguda por lo general se autolimita al cabo de 3-4 semanas, pero hay cuadros crónicos con consecuencias importantes.

Toxoplasmosis adquirida en hospedero inmunocomprometido. Se manifiesta como una infección aguda generalizada con predilección por el sistema nervioso central, ojos, corazón, hígado y pulmones y en general por sitios donde la respuesta inmune es limitada; la infección conduce a lesiones como encefalitis, retinocoroiditis, pericarditis, derrame pericárdico, miocarditis, miositis, neumonía interstidal. En ocasiones se puede manifestar síndrome de Guillain-Barré. Los pacientes con alto riesgo son aquéllos con enfermedad de Hodgkin, los que reciben agentes inmunosupresores o corticosteroides y los pacientes con sida. Los pacientes presentan fiebre elevada, neumonía, erupción cutánea, hepatoesplenomegalia, miocarditis, miositis, orquitis.

Toxoplasmosis congénita. Transmisión vertical debida a infección en la madre durante la gestación, la cual puede ser por reactivación en una infección crónica en la que los bradizoítos presentes en los quistes tisulares revierten a taquizoítos por diferentes causas o por primoinfeción. El daño es más importante cuando la infección se presenta en el primer trimestre 


\section{Un acercamiento a la toxoplasmosis cerebral y su diagnóstico imagenológico}

Vol. 3, núm. 1., (2019)

Carlos Armando Zambrano Zunino; Lissette Yesenia Rosero Ortega; Maria Stephania Limones Moncada; Mariana Yadira Campaña Davila; Jacqueline Amalia Parra Zamora

de la gestación. El sistema ventricular es el más afectado en el neonato, se presenta una obstrucción inflamatoria y en consecuencia hidrocefalia de los ventrículos tercero y lateral, calcificaciones y en los casos más severos destrucción del hipotálamo.

Toxoplasmosis ocular. La toxoplasmosis ocular puede ocurrir en la mayoría de los casos como consecuencia de una toxoplasmosis congénita, sin embargo, puede adquirirse después del nacimiento. El cuadro clínico comprende diferentes signos y síntomas, desde dolor, fotofobia, lagrimeo, visión borrosa, hasta pérdida de la visión. El cuadro, por lo general, es poco específico. ${ }^{4}$

\section{Toxoplasmosis cerebral}

Es una infección oportunista del Sistema Nervioso Central que ocurre especialmente en pacientes inmunocomprometidos (Síndrome de Inmunodeficiencia Adquirida (SIDA) o con trasplante de órganos). Sus formas de transmisión son el contacto directo con animales infectados, consumo de carnes contaminadas y transmisión vertical madre-hijo. Se estima que aproximadamente la mitad de la población mundial ha estado en contacto con sepas de este parásito.

Manifestaciones clínicas:

Consisten en hidrocefalia, corioretinitis y calcificaciones cerebrales (Triada de Sabin). Sin embargo, rara vez se presentan en conjunto. Pueden aparecer convulsiones tónico-clónicas, cefalea, hemiparesias, síndrome motor deficitario, síndrome cerebeloso, alteraciones de la memoria y la concentración, déficit focales en pares craneales; todos dependientes del número y 


\section{Un acercamiento a la toxoplasmosis cerebral y su diagnóstico imagenológico}

Vol. 3, núm. 1., (2019)

Carlos Armando Zambrano Zunino; Lissette Yesenia Rosero Ortega; Maria Stephania Limones Moncada; Mariana Yadira Campaña Davila; Jacqueline Amalia Parra Zamora

localización de lesiones en el SNC. El método de diagnóstico definitivo, se basa en estudios imagenológicos con TC y RM, asociado a hallazgos serológicos y Biopsia.

\section{Diagnóstico por neuroimagen:}

En la TC con contraste y en la RM, se observan lesiones intraparenquimatosas, únicas (15\%) o múltiples (85\%). Estas varían en tamaño desde microscópicas (3-9 milímetros), hasta lesiones de varios centímetros; además presentan centro hipodenso y bordes resaltados compatibles con realce en anillo; en ocasiones lesiones hiperdensas, con realce solido cuando son pequeñas. Se comportan como lesiones con efecto masa asociadas a edema vasogénico circundante y de manera característica, las formas parasitarias se localizan en la periferia de las lesiones.

Sus localizaciones más frecuentes son los ganglios basales, regiones corticales y subcorticales de lóbulos temporal, frontal y parietal. Tanto en la clínica como en la imagenología, la toxoplasmosis cerebral y el Linfoma tienen comportamiento similar, pero guardan algunas diferencias importantes. ${ }^{5}$

La neurotoxoplasmosis (NTX) es una de las infecciones oportunistas más frecuentes en el paciente infectado por el virus de inmunodeficiencia humana y se presenta con diversidad de manifestaciones clínicas en el huésped inmunoafectado

La encefalitis toxoplásmica es la causa más frecuente de infección del sistema nervioso central (SNC), casi siempre como resultado de una reactivación de una infección latente, por el Toxoplasma gondii, y que contraen entre el 25 y el $50 \%$ de los pacientes infectados por el VIH, 


\section{Un acercamiento a la toxoplasmosis cerebral y su diagnóstico imagenológico}

Vol. 3, núm. 1., (2019)

Carlos Armando Zambrano Zunino; Lissette Yesenia Rosero Ortega; Maria Stephania Limones Moncada; Mariana Yadira Campaña Davila; Jacqueline Amalia Parra Zamora

cuando su inmunodepresión celular es intensa, generalmente cuando la población de linfocitos T CD4+ es inferior a $100 / \mathrm{mm}^{3}$.

La toxoplasmosis puede tener catastróficas consecuencias en pacientes inmunodeprimidos si no es tratada, un correcto diagnóstico es dificultoso por la sustancial confusión que puede traer diferenciarla del linfoma primario del sistema nervioso central. Además, tiene una localización profunda en el cerebro, a la cual es difícil acceder para realizar la biopsia, por lo que para su diagnóstico es necesario la interpretación de los hallazgos en las neuroimágenes.

Las técnicas de neuroimagen tienen valor para su diagnóstico, las más empleadas son la TAC y la imagen de resonancia magnética (RMN). La TAC muestra lesiones únicas o múltiples, redondeadas, hipodensas, con edema, efecto de masa, suele captar el contraste en forma de anillo y se encuentran localizadas preferentemente en ganglios basales y en los hemisferios cerebrales; ocasionalmente aparecen calcificaciones y hemorragias. ${ }^{6-7}$

\section{Toxoplasmosis y embarazo}

En más del $90 \%$ de los casos cursa de forma asintomática en la mujer embarazada. La frecuencia de transmisión vertical se incrementa con la edad gestacional. Se estima que la tasa de transmisión al feto es del $15 \%$ si la infección materna es adquirida durante el primer trimestre, $30 \%$ durante el segundo y $60 \%$ en el tercero. La transmisión de la infección al feto a partir de una mujer con infección crónica es muy poco probable, pero puede ocurrir en mujeres con disturbios inmunológicos, como mujeres con SIDA, Linfoma de Hodgkin, o Lupus eritematoso sistémico. La reinfección con Toxoplasma Gondii (T. Gondii) es excepcional, pero puede 


\section{Un acercamiento a la toxoplasmosis cerebral y su diagnóstico imagenológico}

Vol. 3, núm. 1., (2019)

Carlos Armando Zambrano Zunino; Lissette Yesenia Rosero Ortega; Maria Stephania Limones Moncada; Mariana Yadira Campaña Davila; Jacqueline Amalia Parra Zamora

transmitirse al feto cuando esta ocurre durante el embarazo. La PCR es ahora reconocida como una herramienta diagnóstica esencial para la toxoplasmosis congénita. Foulon y otros demostraron que la PCR en el líquido amniótico (LA) tuvo un alto nivel de sensibilidad (81 \%) y también un nivel alto de especificidad $(96 \%) .{ }^{8}$

\section{Diagnóstico}

El diagnóstico de infección durante el embarazo se realiza mediante el tamizado serológico. El beneficio de realizar serología en las mujeres embarazada es controvertido y su aplicación es variable según los países donde se presenta.

Una de las técnicas que se utiliza es la reacción en cadena de la polimerasa (PCR) como herramienta diagnóstica, no obstante, el método inmunológico de mayor empleo en el diagnóstico es el enzyme- linked immunosorbent assay (ELISA). Para comprobar infección en un recién nacido debe encontrarse $\operatorname{IgM}$ en su suero, esta prueba no presenta tanta confiabilidad como se ha propuesto; un valor de IgM específica tiene un bajo valor predictivo para identificar infección primaria por $T$. gondii. También se consideran de gran utilidad el estudio de avidez de IgG, así como la determinación IgA por ISAGA (ambas variantes de ELISA), para el diagnóstico de infección reciente, pero igual tienen la desventaja de poca disponibilidad de la prueba y la persistencia de IgA hasta por un año después de la infección. La técnica de ELISA tiene una gran ventaja por su simplicidad, sensibilidad y especificidad.

El diagnóstico de infección en la embarazada se realiza mediante la demostración de una seroconversión de $\operatorname{IgG}$, por el aumento de tres o más de los títulos de $\operatorname{IgG}$ en dos extracciones consecutivas separadas por 3 a 4 semanas o por la presencia de $\operatorname{IgM}$ positiva con anticuerpos $\operatorname{IgG}$ 


\section{Un acercamiento a la toxoplasmosis cerebral y su diagnóstico imagenológico}

Vol. 3, núm. 1., (2019)

Carlos Armando Zambrano Zunino; Lissette Yesenia Rosero Ortega; Maria Stephania Limones Moncada; Mariana Yadira Campaña Davila; Jacqueline Amalia Parra Zamora

de baja avidez. El resultado de una IgM positiva en el primer trimestre hace sospechar una infección reciente. Sin embargo, ésta puede mantenerse positiva hasta por lo menos dos años, por lo que hay que saber que una IgM positiva durante el embarazo representa una infección reciente solo en un $40 \%$ de los casos. Por lo tanto, antes de decidir cualquier conducta es necesario realizar otras técnicas más sensibles como la inmunofluorescencia indirecta o repetir la IgM Cadena de polimerasa (PCR) del líquido amniótico a partir de la semana 18 de gestación. Esta técnica presenta una sensibilidad entre el $65 \%$ a $92 \%$ y una especificidad cercana al $100 \%$. Parecería que la sensibilidad es superior a la que se obtiene de sangre, orina o LCR del RN por lo que debe ofrecerse siempre ante la sospecha de infección materna en cualquier trimestre.

Otras técnicas de diagnóstico utilizadas Enzimoinmunoensayo (EIA). Existen numerosos equipos comerciales y la falta de uniformidad en el antígeno y en la expresión de los resultados imposibilita la comparación entre ellos. La EIA para IgM tiene las mismas interferencias que la IFI para IgM.

La IFI anti-IgM o test de Remington tiene interferencias. Los títulos elevados de IgG pueden dar lugar a un resultado falso negativo. El factor reumatoideo o el factor antinuclear pueden dar resultados falsos positivos. Se requiere un pretratamiento con una anti-IgG, para eliminar la interferencia.

Reacción de Sabin-Feldman (SF). Según la Organización Mundial de la Salud es la prueba de referencia para infección aguda materna, la evolución fetal se controla con ecografía. Después del parto, se debe evaluar al recién nacido clínica y serológicamente con 


\section{Un acercamiento a la toxoplasmosis cerebral y su diagnóstico imagenológico}

Vol. 3, núm. 1., (2019)

Carlos Armando Zambrano Zunino; Lissette Yesenia Rosero Ortega; Maria Stephania Limones Moncada; Mariana Yadira Campaña Davila; Jacqueline Amalia Parra Zamora

determinaciones de $\operatorname{IgG}$, IgM e $\operatorname{IgA}$. Las IgG atraviesan la placenta y el título obtenido al nacimiento generalmente coincide con el materno.

Títulos de IgG significativamente mayores o la presencia de $\operatorname{IgM}$ y/o $\operatorname{IgA}$, que no atraviesan la placenta, es indicio de infección prenatal. Para la detección de $\operatorname{IgM}$ e $\operatorname{IgA} \operatorname{las}$ técnicas de inmunocaptura son las más adecuadas por su sensibilidad y especificidad. La técnica de ISAGA para la detección de IgM tiene una sensibilidad del $80 \%$ y para $\operatorname{IgA}$ del $83 \%$, la realización de ambas determinaciones incrementa la sensibilidad al 91.4\% Aun con estas pruebas negativas el niño será considerado libre de infección recién cuando las IgG, supuestamente de origen materno, se hayan negatividad. La persistencia de IgG al año confirma la infección prenatal.

El hallazgo de estas inmunoglobulinas, que no atraviesan placenta, en sangre del recién nacido es indicio de infección prenatal. Aglutinación directa (AD). Es una técnica sencilla y accesible a laboratorios de baja complejidad.

Prueba de avidez de los anticuerpos (P-A). Se basa en la baja avidez que presentan los anticuerpos IgG por los antígenos parasitarios en los primeros 3 a 5 meses de la infección. Con la maduración de la respuesta inmune los anticuerpos adquieren mayor avidez. En el primer trimestre de un embarazo la detección de anticuerpos con alta avidez, permite descartar una infección reciente. Una baja avidez sugiere una infección reciente pero no es confirmatoria y se debe interpretar en el contexto del panel de reacciones realizadas.

Reacción en cadena de la polimerasa (PCR). Permite detectar fracciones de ADN del parásito en muestras de sangre del cordón o del líquido amniótico es útil para diagnosticar 


\section{Un acercamiento a la toxoplasmosis cerebral y su diagnóstico imagenológico}

Vol. 3, núm. 1., (2019)

Carlos Armando Zambrano Zunino; Lissette Yesenia Rosero Ortega; Maria Stephania Limones Moncada; Mariana Yadira Campaña Davila; Jacqueline Amalia Parra Zamora

infección prenatal. Por otro lado la técnica de reacción en cadena de polimerasa (PCR) en sangre, orina o líquido cefalorraquídeo (LCR), que en nuestro país no está aún estandarizada, presenta una buena especificidad pero menor sensibilidad, por lo que un resultado negativo no excluye la infección.

En estos casos, el único marcador diagnóstico de infección es la IgG. Existe una fuerte caída de la misma en los dos meses posteriores al nacimiento, mientras que luego el descenso es más lento. De existir infección congénita éste marcador se estabiliza o asciende de forma significativa a los seis meses de vida o persiste reactivo luego del año de vida.

\section{Tratamiento}

Actualmente, se cuenta con varios tratamientos con moléculas inhibidoras de la síntesis de folatos que el parásito sintetiza. Las principales moléculas son la espiramicina, la pirimetamina y las sulfonamidas, que son implementadas y recomen- dadas para minimizar la gravedad de las consecuencias por esta infección. ${ }^{3}$

La toxoplasmosis es la principal causa de morbidez neurológica y mortalidad en pacientes con SIDA, provocando trastornos neurológicos y psicomotores en niños infectados congénitamente, constituyendo un motivo de preocupación y controversia, por lo que se hace necesario, antes de indicar cualquier tratamiento, un diagnóstico cuidadoso de la infección en el laboratorio. ${ }^{9}$ 


\section{Un acercamiento a la toxoplasmosis cerebral y su diagnóstico imagenológico}

Vol. 3, núm. 1., (2019)

Carlos Armando Zambrano Zunino; Lissette Yesenia Rosero Ortega; Maria Stephania Limones Moncada; Mariana Yadira Campaña Davila; Jacqueline Amalia Parra Zamora

En los pacientes con antecedentes de toxoplasmosis o con conteo de células CD4+ por debajo de $100 \mathrm{cel} / \mathrm{mm} 3$, se ha propuesto como terapéutica preventiva trimetropin-sulfadiazina (800 mg), 1 tab, 3 v/sem.

En la infección aguda se recomienda el uso combinado de 3 medicamentos: pirimetamina (daraprín): 100 a 200 mg como dosis inicial y después de 50 a 100 mg diarios; sulfadiacina: 1-2 g c/6 h por vía EV y ácido fólico (leucovarín) $10 \mathrm{mg}$ diarios (para prevenir la depresión de la médula ósea) durante 6 a 8 semanas. ${ }^{10}$

\section{Prevención de la infección por Toxoplasma gondii}

Se han conocido de diferentes experiencias internacionales en la prevención de esta patología, existiendo controversia sobre la efectividad de los programas de tamizaje y educación de la población en riesgo. Estas acciones están dentro del área de la medicina preventiva, cuyos objetivos es prolongar la vida, disminuir la morbilidad y mejorar la calidad de vida de los pacientes. Dentro de sus acciones:

- La prevención primaria, está dirigida a minimizar los factores de riesgos y la aparición posterior de enfermedades, considerando en esta etapa las vacunaciones y determinadas formas de promoción de la salud.

- La prevención secundaria, está basada en realizar diagnóstico precoz de la enfermedad, muchas veces en su forma asintomática; esto ha sido relevante en programas de control en otros países. En Francia, antes de 1992 había una prevalencia en mujeres embarazas de 59,4\%; a partir de ese año se puso en marcha diferentes acciones de educación a la población y evaluación serológica, con lo cual 


\section{Un acercamiento a la toxoplasmosis cerebral y su diagnóstico imagenológico}

Vol. 3, núm. 1., (2019)

Carlos Armando Zambrano Zunino; Lissette Yesenia Rosero Ortega; Maria Stephania Limones Moncada; Mariana Yadira Campaña Davila; Jacqueline Amalia Parra Zamora

bajaría la prevalencia a $46,6 \%(\mathrm{p}: 0,038)^{66}$. Estas medidas permitieron un mejor seguimiento y apoyo a mujeres embarazadas susceptibles (seronegativas para toxoplasmosis), además de la oportuna intervención terapéutica, para disminuir el riesgo de toxoplasmosis congénita. Esto último no se ha alcanzado completamente. Sí se ha establecido que el modelo de Francia aplicado a la realidad de Estados Unidos., permitiría bajar los costos basado en criterios públicos de mantención de discapacidades de por vida, costos de diagnósticos y tratamientos actuales.

- La prevención terciaria es la asistencia dirigida a mejorar el curso evolutivo de una enfermedad. En este sentido, Francia estableció diferentes medidas para dar término al embarazo en caso de existir complicaciones graves en el feto, cuya presentación clínica sea irreversible.

Dentro de estas actividades en Salud, la prevención primaria es de primera elección en cualquier programa de prevención y control de alguna enfermedad, pero para ello es necesario tener un conocimiento más profundo de la enfermedad en la población, en cuanto a sus mecanismos de transmisión, manifestaciones clínicas más frecuentes y situaciones de riesgo particulares. ${ }^{1}$

En los casos de los pacientes inmunodeprimidos y embarazadas seronegativas a este parásito se hace necesario que cumplan las siguientes medidas higiénicas sanitarias:

- Cocción adecuada de los alimentos y en especial de las carnes.

- Beber agua potable.

- Lavarse las manos con agua y jabón antes de ingerir alimentos. 


\section{Un acercamiento a la toxoplasmosis cerebral y su diagnóstico imagenológico}

Vol. 3, núm. 1., (2019)

Carlos Armando Zambrano Zunino; Lissette Yesenia Rosero Ortega; Maria Stephania Limones Moncada; Mariana Yadira Campaña Davila; Jacqueline Amalia Parra Zamora

- Lavar las verduras y frutas antes de consumir.

- Si se trabaja con tierra, protegerse con guantes y máscara.

- Tener especial cuidado con los gatos. Preferiblemente, este tipo de pacientes debe evitar el contacto con los gatos y en especial con sus heces. Si tiene que realizar el cambio de la arena higiénica, debe realizarlo con máscara y guantes. Después lavarse bien las manos.

- Mantener los gatos dentro de la casa para que no salgan de cacería y alimentarlos con carnes bien cocidas. ${ }^{9}$

\section{Conclusiones}

La Toxoplasmosis es una enfermedad infecciosa causada por el Toxoplasma gondii, que se transmite al hombre por la vía oral (la más frecuente), la vía transfusional, trasplantes de órganos, la vía acuática, la mecánica, por inhalación y la vía sexual, sus manifestaciones clínicas varían desde las formas asintomáticas hasta las que se producen en un hospedero inmunodeprimido que se caracteriza por una infección aguda generalizada con predilección por el sistema nervioso central, ojos, corazón, hígado y pulmones y en general por sitios donde la respuesta inmune es limitada.

La neurotoxoplasmosis (NTX) es una de las infecciones oportunistas más frecuentes en el paciente infectado por el virus de inmunodeficiencia humana y se presenta con diversidad de manifestaciones clínicas en el huésped inmunoafectado. El método de diagnóstico definitivo, se basa en estudios imagenológicos con TC y RM, asociado a hallazgos serológicos y Biopsia. El tratamiento preventivo es de vital importancia para el control de la enfermedad. 


\section{Un acercamiento a la toxoplasmosis cerebral y su diagnóstico imagenológico}

Vol. 3, núm. 1., (2019)

Carlos Armando Zambrano Zunino; Lissette Yesenia Rosero Ortega; Maria Stephania Limones Moncada; Mariana Yadira Campaña Davila; Jacqueline Amalia Parra Zamora

\section{Bibliografía.}

1. Mimica Francisco, Muñoz-Zanzi Claudia, Torres Marisa, Padilla Oslando. Toxoplasmosis, zoonosis parasitaria prevalente en Chile: recuento y desafíos. Rev. chil. infectol. [Internet]. 2015 Oct [citado 2019 Mar 17] ; 32 5 ): 541-549. Disponible en: https://scielo.conicyt.cl/scielo.php?script=sci_arttext\&pid=S0716-

10182015000600008\&lng=es. http://dx.doi.org/10.4067/S0716-10182015000600008

2. Hernández-cortazar I, Acosta-viana karla y., Ortega-pacheco A, Guzman-marin Eugenia del s., Aguilar-caballero armando j., Jiménez-coello M. Toxoplasmosis in Mexico: Epidemiological Situation in Humans and Animals. Rev Inst Med Trop Sao Paulo [Internet]. 2015;57(2):93-103. Available from: http://www.scielo.br/scielo.php?script=sci_arttext\&pid=S003646652015000200093\&lng $=$ en\&nrm=iso\&tlng=en

3. Cañon Álzate LT. Factores de riesgo y prevalencia de toxoplasmosis en países tropicales. Trabajo de grado para aspirar al título de Medicina Veterinaria y Zootecnia. Universidad Tecnológica de Pereira Programa de Medicina Veterinaria y Zootecnia Pereira Risaralda, 2017. Disponible en: https://core.ac.uk/download/pdf/92123716.pdf

4. Rivera Fernández Norma, García Dávila Paola. The role of cats in toxoplasmosis. Reality and responsibility. Rev. Fac. Med. (Méx.) [revista en la Internet]. 2017 Dic [citado 2019 Mar 17]; $60 \quad$ (6): $\quad 7-18 . \quad$ Disponible en: http://www.scielo.org.mx/scielo.php?script=sci_arttext\&pid=S0026$17422017000600007 \& \operatorname{lng}=\mathrm{es}$.

5. Aljure V, Pulido-Arias E, Rodríguez-Monroy J, Rodríguez-Mateus M, Ramos-Hernández M. Diagnóstico diferencial de lesiones cerebrales con realce en anillo en tomografía computarizada y resonancia magnética. Duazary. 2016 julio; 13 (2): 149 - 158. Disponible

en: http://revistas.unimagdalena.edu.co/index.php/duazary/article/view/1721/1218

6. Parra Morales R, Rubio Rodríguez A, Alejandro Garcell A, Ricardo Aguilera N, Sánchez Peña J. Comportamiento clínico de la neurotoxoplasmosis en pacientes con sida. CCM. 2010[citado 23 mar 2012]; 14(4): Disponible en: http://www.cocmed.sld.cu/no144/no144ori02.htm

7. Cordovés Molina Katiuska, Zaldívar Pérez Luis Mario, Camejo González Nancy, Ricardo Bermúdez Leticia, Cruz Rivas Edilia. Neurotoxoplasmosis diagnosticada por tomografía axial computarizada en un paciente con sida. ccm [Internet]. 2015 Mar [citado 2019 $\begin{array}{llllll}\text { Mar 17] } & \text {; } 19(173-179 . \quad \text { Disponible en: }\end{array}$ http://scielo.sld.cu/scielo.php?script=sci_arttext\&pid=S156043812015000100020\&lng=es. 


\section{Un acercamiento a la toxoplasmosis cerebral y su diagnóstico imagenológico}

Vol. 3, núm. 1., (2019)

Carlos Armando Zambrano Zunino; Lissette Yesenia Rosero Ortega; Maria Stephania Limones Moncada; Mariana Yadira Campaña Davila; Jacqueline Amalia Parra Zamora

8. Sánchez Lombana Rita, Couret Cabrera Martha Patricia, Ginorio Gavito Doris, Nodarse Rodríguez Alfredo, Sánchez Ramírez Niobys, Soler Guibert Irina et al . Toxoplasmosis and pregnancy. Rev Cubana Obstet Ginecol [Internet]. 2012 Mar [citado 2019 Mar 17] ; 38( 1 ): 99-106. Disponible en:

http://scielo.sld.cu/scielo.php?script=sci_arttext\&pid=S0138600X2012000100012\&lng=es.

9. Martín Hernández I, García-Izquierdo SM. Toxoplasmosis en el hombre. Bioquimia, 2003, vol 28 (3): 19-27. Disponible en: http://www.medigraphic.com/pdfs/bioquimia/bq2003/bq033d.pdf

10. Casanova Sotolongo P, Casanova Carrillo P, Casanova Carrillo C. Toxoplasmosis cerebral durante la infección por el virus de inmunodeficiencia humana. Rev cubana med [Internet]. 2002 Oct [citado 2019 Mar 18] ; 41( 5 ): 297-302. Disponible en: http://scielo.sld.cu/scielo.php?script=sci_arttext\&pid=S0034$75232002000500010 \& \operatorname{lng}=$ es. 